
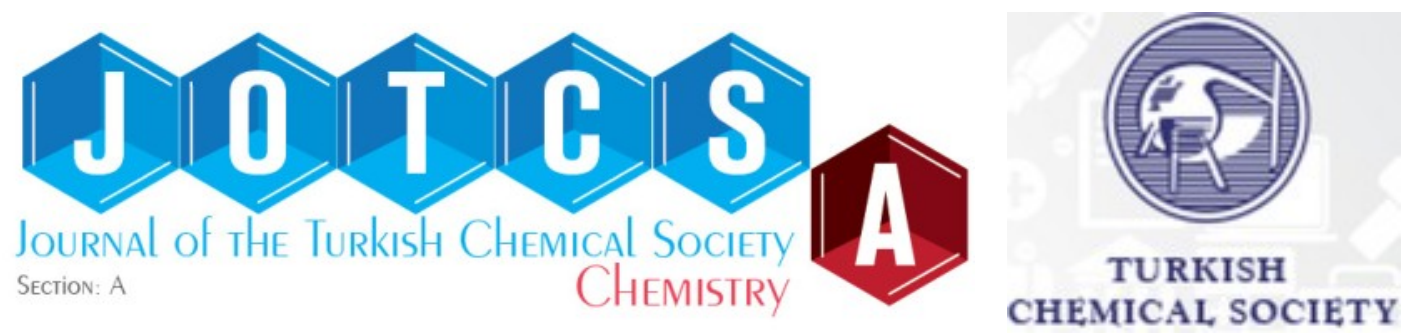

\title{
Determination of Contents of Rutin and Quercetin Isolated from Syrian Ficus carica L. Leaf Extracts
}

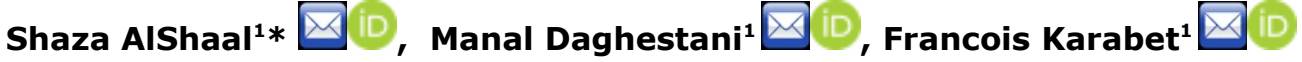 \\ ${ }^{1}$ Department of Chemistry, Faculty of Sciences, Damascus University, Syria.
}

\begin{abstract}
The major flavonoid glycoside in Syrian Ficus carica L. leaf extracts (rutin) was identified quantitatively and isolated, then transformed into its aglycone (quercetin) by acidic hydrolysis of ethanolic and aqueous extracts. The influence of the hydrolysis process on isoquercitrin content was investigated, too. The determination of contents of Rutin and Quercetin isolated from Syrian Ficus carica L. leaf extracts was carried out by high performance liquid chromatography, and the isolation was done by using thin layer chromatography plates, then identified by mass spectra. Results showed that rutin content in the ethanolic extract $(78.79 \%)$ was higher than the aqueous one $(61.90 \%)$ by using ultrasonic extraction procedure. The quercetin content by hydrolysis process was more satisfactory in the ethanolic extract $(81.00 \%)$ than the aqueous one $(72.53 \%)$. Acidic hydrolysis process destroyed some of the isoquercitrin in the extracts. The detection of isoquercitrin was done qualitatively by noticing the mass spectrum and the photo diode array spectrum. Rutin and quercetin were successfully isolated, the relative peak areas for isolated rutin and quercetin were $99.80 \%$ and $96.46 \%$, respectively. It was concluded that rutin can be easily converted into quercetin by acidic hydrolysis, allowing the use of Syrian ficus leaf extracts as an optimal cheap natural antioxidant source.
\end{abstract}

Keywords: Syrian Ficus carica L. leaf, rutin, quercetin, isoquercitrin.

Submitted: September 20, 2019. Accepted: November 21, 2019.

Cite this: AlShaal S, Daghestani M, Karabet F. Determination of Contents of Rutin and Quercetin Isolated from Syrian Ficus carica L. Leaf Extracts. JOTCSA. 2020;7(1):199-208.

DOI: https://doi.org/10.18596/jotcsa.622442.

*Corresponding author. E-mail: shazamalshaal@gmail.com.

\section{INTRODUCTION}

Ficus carica L. (Moraceae) is a native bush of South West Asia cultivated since years ago. There are at least 800 kinds of ficus known worldwide, originally from Persia and Syria, spread later in Europe and America (1). Ficus carica is vastly cultivated over Syria, mainly as individual trees in private gardens for family consumption. The total Syrian ficus cultivated area is ca. 9,663 ha, with an estimated sum production of about $53.7 \times 10^{3}$ tones (2). Part of the plants, the bark, root, leaf and fruit are often used to overcome various diseases. Ficus species are known to be wealthy of polyphenolics and flavonoids which are correlated to the antioxidant power (3). There are enormous reports on the plant's bioactivities, which are potential to overcome many diseases (4) such as Haemostatic, antiHerpes Simplex Virus (HSV), hypolipidemic, hypoglycemic (5) and anticancer (6). The power of flavonoids to act as antioxidants depends upon their molecular structure (7). The hydroxyl groups play a role in the antioxidant and free radical scavenging activities of flavonoids, by rapid donation of a hydrogen atom to radicals (equations 1 and 2 ),

$$
\mathrm{R}+\mathrm{phOH} \rightarrow \mathrm{RH}+\mathrm{phO}
$$




$$
\mathrm{phO}+\mathrm{R} \cdot \rightarrow \mathrm{phOR}
$$

where phOH stands for phenolic compounds. Quercetin is considered as a reference substance for measuring the antioxidant activity (8). Quercetin accumulates in plants as glycosides such as glucosides, rutinosides (9). In nature there are more than 180 glycosides of quercetin in different structures, the most popular is rutin (10). Rutin (quercetin-3-Orutinoside) is composed of one molecule of quercetin as aglycone and rutinose. Although there is structural similarity in rutin, isoquercitrin (isoquercetin) and quercetin, as shown in Figure 1 (11) there are some remarkable differences in physical, chemical and biological properties (12).

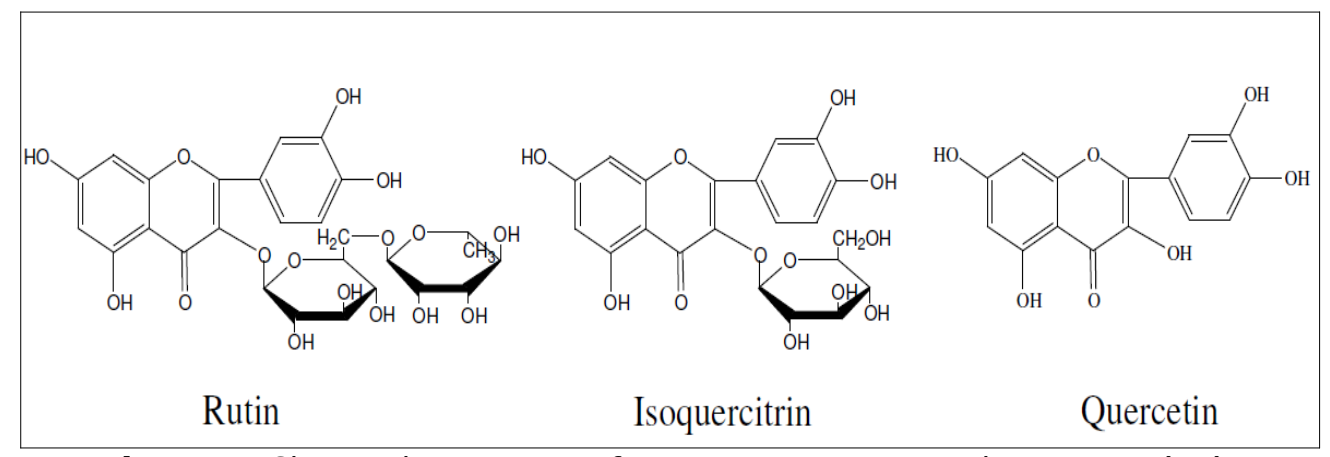

Figure 1. Chemical structures of rutin, isoquercitrin and quercetin (11).

Rutin is the master flavonoid glycoside found in ficus (13). It can be converted to quercetin the aglycone form, via breaking one terminal rhamnose by hydrolysis process; also it can be converted to isoquercitrin which has more advantageous than rutin, because of its better bioavailability and more anti-proliferative effect than rutin and quercetin (14). Rutin is an important food component necessary for human health since it affects the capillary fragility and positively permeability (15). It has a protective effect on the expansion of diabetes and mitigates the effects on the consequences of diabetes $(16,17)$. Studies indicate that rutin has many functional properties such as antioxidant, anti-inflammatory effect in humans (18). However, its antioxidant activity and its bioavailability were lower than quercetin in rats by oral management (19-21). The disadvantage of quercetin is poorly absorbed in the small intestine, and the bioavailability of it was mentioned to be less than one per cent in the capsule form in human beings (22). Lately, isoquercitrin has attracted attention as a promising compound because of its higher solubility than quercetin in aqueous solutions $(11,23)$, but its antioxidant activity is a little lower than that of quercetin (24). It is eligible to maximize the production of isoquercitrin together with quercetin during the hydrolysis of rutin (11). The aim of this research was to determine the amount of the major important flavonoid (rutin) in aqueous and ethanolic extracts of Syrian Ficus leaf, hydrolyze it to produce quercetin, then isolate both of rutin and quercetin by Thin Layer Chromatography (TLC) and HPLC-MS techniques. The effect of hydrolysis process on isoquercitrin content was also studied.

\section{EXPERIMENTAL}

\section{Plant material}

Ficus leaves were collected on April 2017 from Banias (Latakia-Governorate), Syria. The plant was identified by Prof. Jurjet Babojian (Department of Plant Biology, Faculty of science, Damascus University, Syria). The ficus leaves were dried in the shade away from the sunlight for 10 days, ground with an electric mill, then stored in a dark, dry, tightly sealed container at room temperature until use.

\section{Chemicals}

Rutin hydrate (95\%), quercetin $(98.0 \%)$ and HPLC grade acetonitrile $(99.9 \%)$ were purchased from Sigma-Aldrich. Ethanol $(99.8 \%)$, acetic acid $(99.5 \%)$, formic acid and $\mathrm{HCl}$ (36.5-39.0\%) from Panreac, toluene $(99.5 \%)$ for the analytical grade from Scharlau, ethyl acetate (99\%) for general purpose reagent from $\mathrm{BDH}$ chemicals Ltd. pool England.

\section{Instruments}

Vortex MS1 Mini shaker (KAI) was used to homogenize ficus leaf powder with solvent, ultrasonic water bath Transsonic Model 460/H (Elma) was used for extraction procedure. High Performance Liquid Chromatography (HPLC) (KNAUER, Germany) and HPLC-MS (Shimadzu, Japan) were used for separation and identification of rutin and quercetin. In order to isolate rutin and quercetin silica gel 60 F254 pre-coated plates $(5 * 20 \mathrm{~cm} /$ layer thickness 


\section{$0.25 \mathrm{~mm}$ ) from MERCK were used.}

\section{Preparation of extracts}

Ultrasonic extraction method was used for its ability to improve extraction by speeding up the release of bioactive substances from cell walls and facilitating their ease of transference (25). One gram of ficus leaf powder was added to 10 $\mathrm{mL}$ of ethanol $70 \%$, was stirred well by piping for homogenization for one minute, then placed in ultrasonic bath at $75{ }^{\circ} \mathrm{C}$, for 30 minutes, filtered from $0.45 \mu \mathrm{m}$ filters and kept in a refrigerator $\left(4^{\circ} \mathrm{C}\right)$ until use. The aqueous extracts were prepared in the same way with $10 \mathrm{~mL}$ distilled water. The experiments were repeated three times.

\section{Hydrolysis of plant extracts}

To convert rutin into quercetin, according to the method presented by Chen et al., (26), acid hydrolysis was mainly completed by adding 2.0 $\mathrm{mL}(2.8 \mathrm{M}) \mathrm{HCl}$ to $2.0 \mathrm{~mL}$ of ficus leaf extracts, then placed in water bath at $90^{\circ} \mathrm{C}$, for different periods (5, 7, and $10 \mathrm{~min}$.$) , placed in cool at$ room temperature $\left(25^{\circ} \mathrm{C}\right)$ for 30 minutes, passed from the filter $(0.45 \mu \mathrm{m})$ and kept in a refrigerator $\left(4{ }^{\circ} \mathrm{C}\right)$ until analyzed. The experiment was repeated three times.

\section{Determination of rutin and quercetin in leaf extracts by HPLC-PDA}

HPLC system (KNAUER 2850) with 4050 pump, column oven, and 2850 PDA (Photo Diode Array) Detector was employed. For determination of rutin from ficus leaf extracts, HPLC method was used with $\mathrm{C}_{18}$ column Eurospher $\left(C_{18}, 250 \mathrm{~mm} \times 4.6 \mathrm{~mm} \mathrm{ID}, 5 \mu \mathrm{m}\right)$ with mobile phase gradient program, consisting of $\mathrm{A}$ : water and $\mathrm{B}$ :acetonitrile (containing $0.3 \%$ acetic acid) as depicted in Table 1 , at a flow rate of $0.9 \mathrm{~mL} / \mathrm{min}$. PDA detector at $370 \mathrm{~nm}$ was used for rutin and quercetin determination. The injection volume used was $20.0 \mu \mathrm{L}$ for both standards and sample solutions. The extracts were injected 3 times.

Table 1. Solvents gradient program for separation of ficus leaf extracts by HPLC-PDA

\begin{tabular}{ccc}
\hline Time/min & A & B \\
\hline 0 & 90 & 10 \\
15 & 50 & 50 \\
20 & 40 & 60 \\
25 & 20 & 80 \\
30 & 20 & 80 \\
35 & 90 & 10 \\
40 & 90 & 10 \\
\hline
\end{tabular}

Identification of rutin and quercetin in ficus leaf extracts were based on comparison of retention times of rutin and quercetin with standards. That is concentration of rutin and quercetin in the extracts were calculated using the peak area of the calibration curves obtained from standard solutions. The concentrations were expressed as $\mathrm{mg} / \mathrm{g}$.

\section{Thin layer chromatography (TLC)}

In this study thin layer chromatography (TLC) was used to separate and identify both quercetin and rutin, from Syrian ficus leaf extracts, which is a simple, cheap and more easily available chromatographic method at research laboratories. It is more time-effective compared to high-performance liquid chromatography. TLC is considered as a public analytical technique, exceedingly used for plant constituents (27). Available standards (rutin and quercetin) and ficus leaf extracts (ethanolic and aqueous) before and after hydrolysis, were run on glass-backed silica gel TLC GF254 pre- coated plate. The optimal solvent for the identification of compounds were determined by varying the ratios of various solvents for developing the solvent system, the more suitable one was: (toluene/ethyl acetate/formic acid) $(9 / 8 / 0.2 \mathrm{v} / \mathrm{v} / \mathrm{v})$ for 30 minutes. The plates were dried at room temperature for 15 minutes, and visualized by exposure to UV light $(366 \mathrm{~nm})$. The bands of the desired compounds in the extracts were collected, dissolved in 0.5 $\mathrm{mL} 70 \%$ ethanol, centrifuged (1000 rpm) at room temperature $\left(25^{\circ} \mathrm{C}\right)$ for 10 minutes, then filtered with $0.45 \mu \mathrm{m}$ filters for HPLC-MS analysis.

\section{Identification of rutin and quercetin and isoquercitrin by HPLC-MS}

HPLC system (Shimadzu) with LC-20ADXR pump, CTO-20A column oven, and SPD-20A UV detector was employed. For determination of rutin, quercetin and isoquercitrin in ficus leaf extracts, HPLC method was used with $\mathrm{C}_{18}$ column $\left(\mathrm{C}_{18}, 250 \mathrm{~mm} \times 4.5 \mathrm{~mm}\right.$ ID, $\left.5 \mu \mathrm{m}\right)$ with 
the same mobile phase gradient program mentioned in Table 1 . The operating conditions of mass spectrometry were: ESI source was operated in negative mode to generate $(\mathrm{M}-\mathrm{H})^{-}$ ions with the following conditions: interface temperature $350{ }^{\circ} \mathrm{C}$; dry gas (nitrogen) and nebulizing gas flow was $1.5 \mathrm{~L} / \mathrm{min}$. Detector and interface voltages were $0.5 \mathrm{KV}$ and $4.5 \mathrm{KV}$, respectively.

\section{RESULTS AND DISCUSSION}

\section{HPLC-PDA results}

Figures 2 and 3 show the HPLC-PDA chromatograms for the ethanolic ficus leaf extracts before and after acid hydrolysis, respectively. The major component in the extracts is rutin, the quercetin content in the extract is almost traces, shown in Figure 2. However, after hydrolysis, the extract contained only traces of rutin and all the glycosidic bonds, as well as isoquercitrin, were ruined, resulted in an ultimate increase in quercetin as shown in Figure 3. The PDA spectrums of rutin, isoquercitrin, and quercetin, respectively also included.

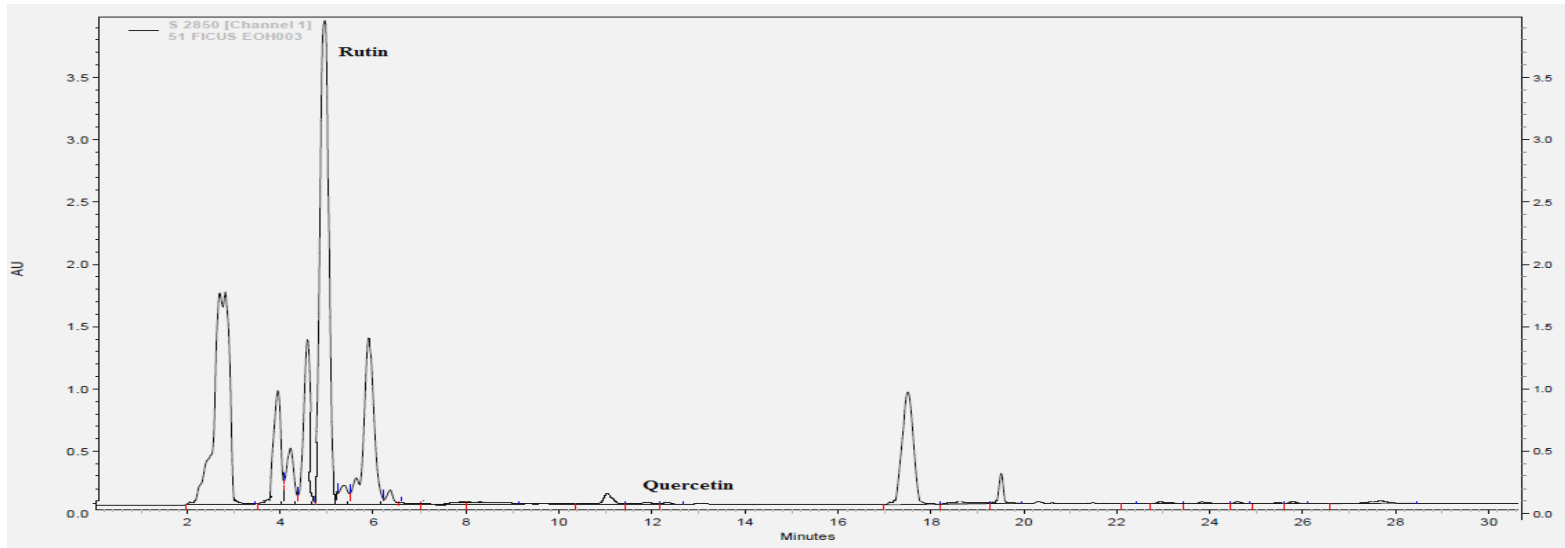

Figure 2. HPLC-PDA chromatogram of ethanolic ficus leaf extract. flow rate $0.9 \mathrm{~mL} / \mathrm{min}$, wavelength at $370 \mathrm{~nm}, \mathrm{C}_{18}$ column $\left(\mathrm{C}_{18}, 250 \mathrm{~mm} \times 4.5 \mathrm{~mm}\right.$ ID, $\left.5 \mu \mathrm{m}\right)$ with gradient mobile phase program.

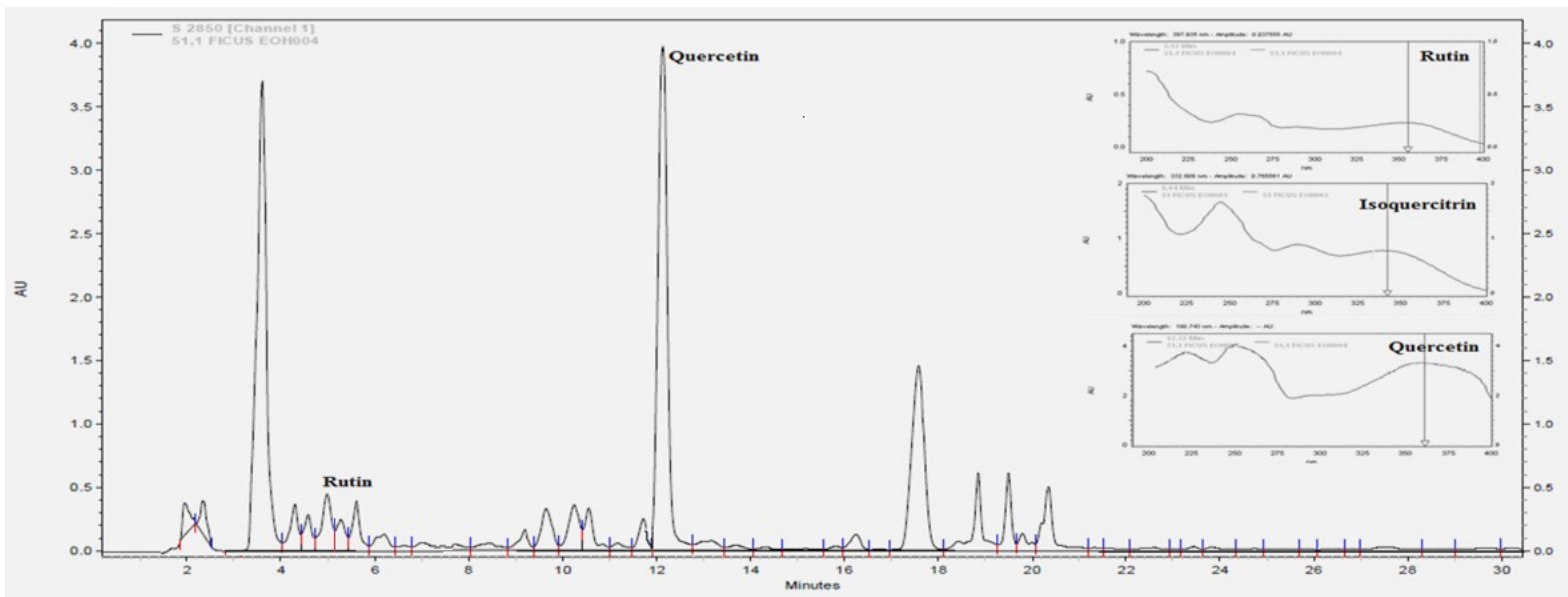

Figure 3. HPLC-PDA chromatogram of hydrolyzed ethanolic ficus leaf extract. The inset figures represent the PDA spectrums of rutin, isoquercitrin and quercetin, respectively.

3-D plots of the UV spectra for ethanolic ficus leaf extracts to illustrate the transformation of rutin into quercetin after the acid hydrolysis process, are shown in Figure 4, where (a) represents rutin and (b) represents quercetin. 


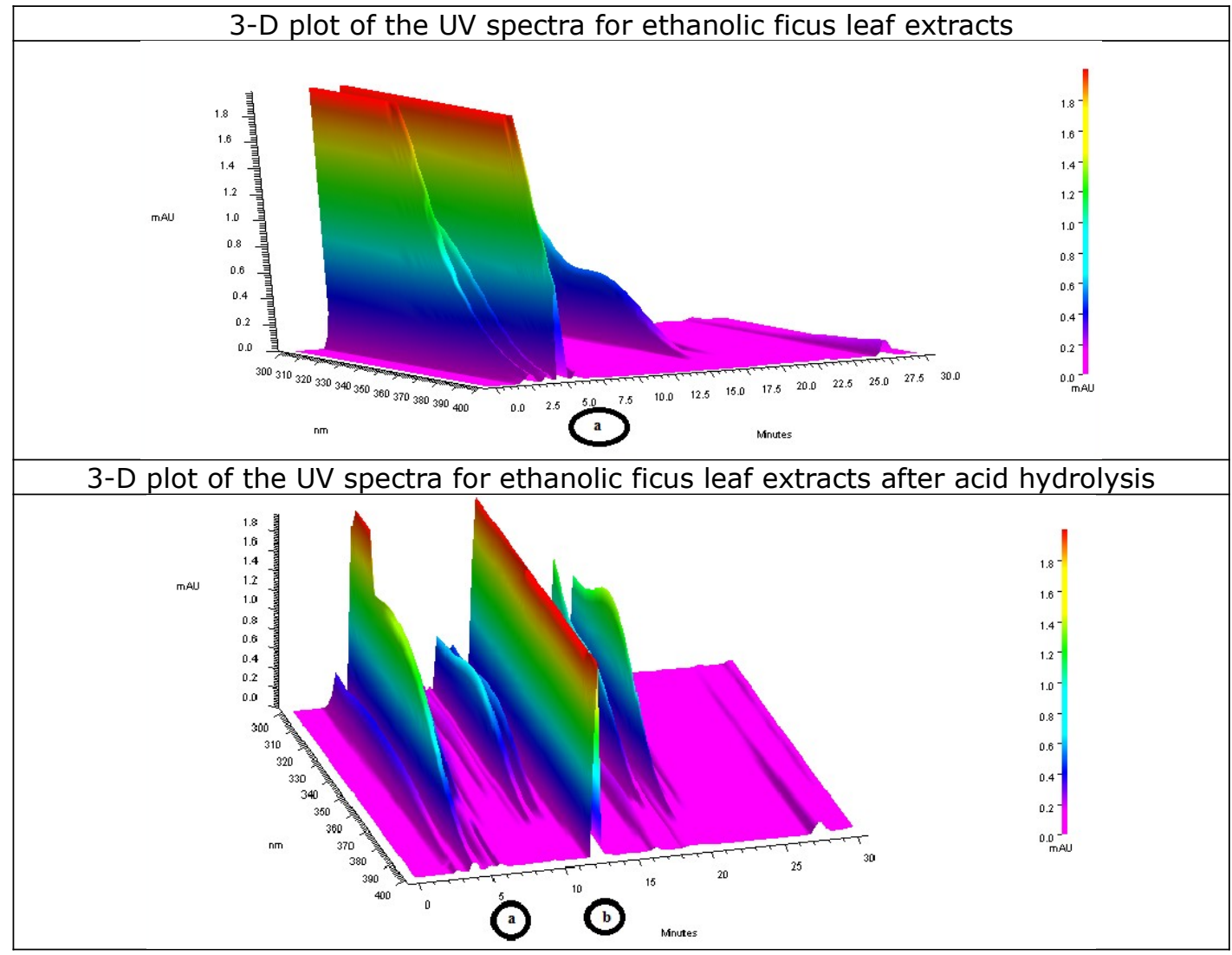

Figure 4. 3-D plots of the UV spectra ethanolic ficus leaf extracts before and after acid hydrolysis (a) rutin, (b) quercetin

Table 2 shows that the ethanolic extract contained a higher concentration of rutin $(16.82 \pm 0.06 \mathrm{mg} / \mathrm{g}$ ) compared to the aqueous extract $(7.87 \pm 0.02 \mathrm{mg} / \mathrm{g})$. This phenomenon might be attributed to the higher viscosity of water than that of the other solvents, which is a matter of mass transfer. Therefore, the mixture of water and ethanol as solvent agent showed the best performance to extract polyphenols of all the extraction solvents used (28). Figure 5 shows a comparison between the relative peak areas\% of the components in the ethanolic and aqueous extracts, before and after the hydrolysis process.

Table 2. Content of rutin and quercetin in Syrian ficus leaf and relative peak area\% before and after acidic hydrolysis

\begin{tabular}{|c|c|c|c|c|c|}
\hline & \multicolumn{2}{|c|}{ Rutin } & \multicolumn{2}{|c|}{ Quercetin } \\
\hline & & $\begin{array}{l}\text { Concentration } \\
(\mathrm{mg} / \mathrm{g})\end{array}$ & $\begin{array}{c}\text { Relative } \\
\text { peak } \\
\text { Area } \%\end{array}$ & $\begin{array}{c}\text { Concentration } \\
(\mathrm{mg} / \mathrm{g})\end{array}$ & $\begin{array}{c}\text { Relative } \\
\text { peak } \\
\text { Area } \%\end{array}$ \\
\hline \multirow[t]{2}{*}{ Extract } & Ethanolic & \multirow{2}{*}{$\begin{array}{c}16.820 \pm 0.060 \\
7.870 \pm 0.020\end{array}$} & 78.79 & \multirow{2}{*}{$\begin{array}{l}0.001 \pm 0.010 \\
0.003 \pm 0.010\end{array}$} & 0.02 \\
\hline & Aqueous & & 61.90 & & 0.06 \\
\hline \multirow[t]{2}{*}{ Hydrolysis } & Ethanolic & \multirow{2}{*}{$\begin{array}{l}1.170 \pm 0.020 \\
0.290 \pm 0.010\end{array}$} & 4.32 & \multirow{2}{*}{$\begin{array}{l}6.950 \pm 0.100 \\
3.300 \pm 0.090\end{array}$} & 81.00 \\
\hline & Aqueous & & 2.03 & & 72.53 \\
\hline
\end{tabular}

Values represent mean $\pm S D, n=3$ 


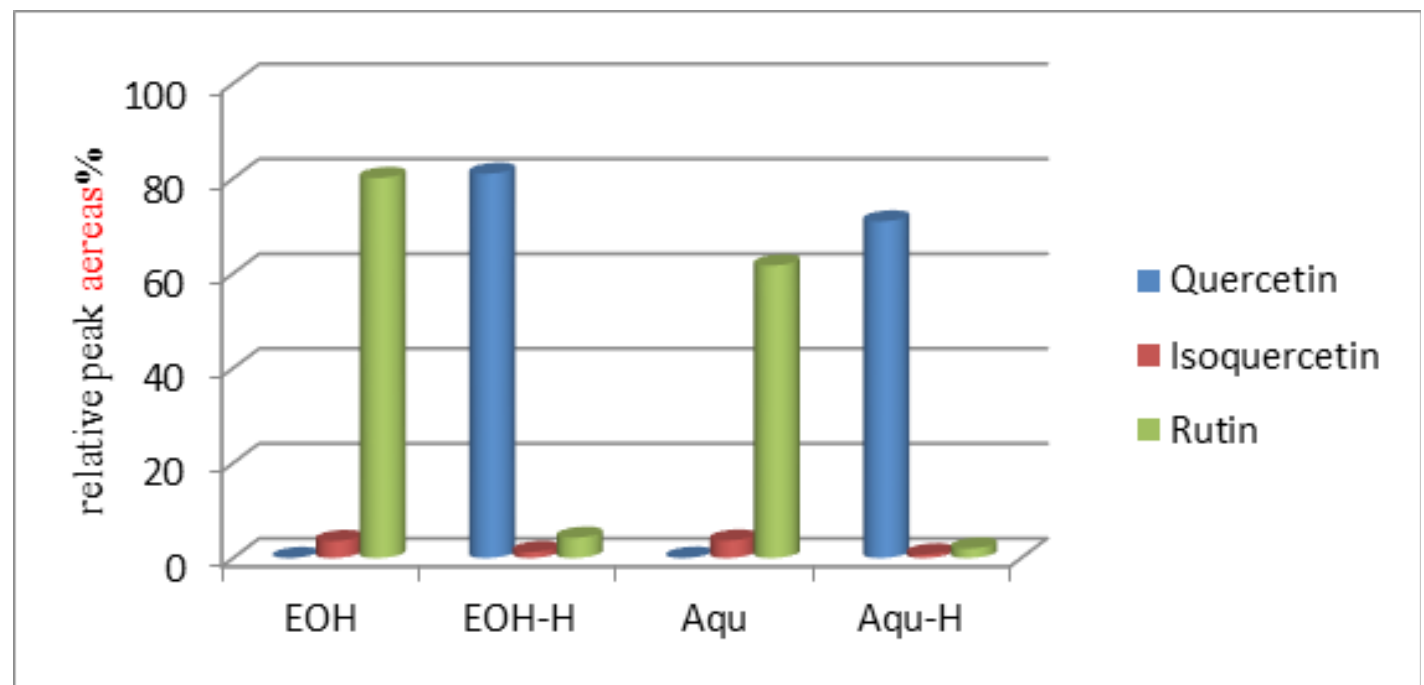

Figure 5. The effect of acid hydrolysis on relative peak areas \% of rutin, isoquercitrin and quercetin in ethanolic, aqueous extracts.

The effect of acid hydrolysis time on quercetin formation was investigated, by hydrolyzing the extracts in different periods of time $(5,7$, and 10 minutes). The greatest amount of hydrolyzed quercetin was measured at 7 minutes then decreased at 10 minutes (Figure $6)$. However, since the hydrolysis process broke isoquercitrin, rutin hydrolyzed for only 5 minutes, in order to preserve isoquercitrin in the extracts.

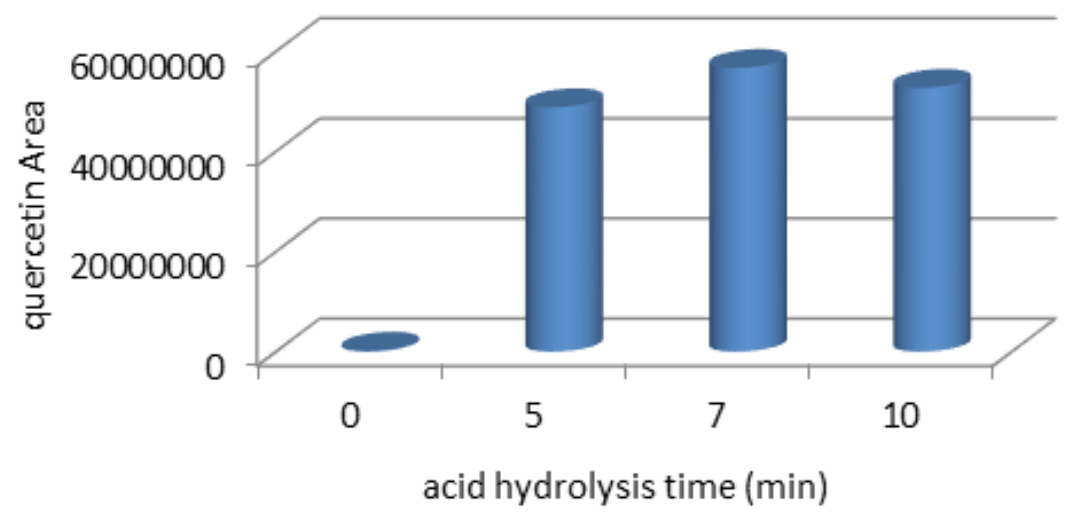

Figure 6. The effect of acid hydrolysis time on the quercetin formation.

Identification and isolation of rutin and quercetin by TLC

Figure 7 shows the TLC plates of ficus leaf extracts before and after acid hydrolysis under UV light $(366 \mathrm{~nm})$. The bands of the desired compounds, (rutin is the third one in (a)), (quercetin is the fourth one in (b)) were collected, dissolved in $0.5 \mathrm{~mL} 70 \%$ ethanol, centrifuged, then prepared for HPLC-MS analysis. 


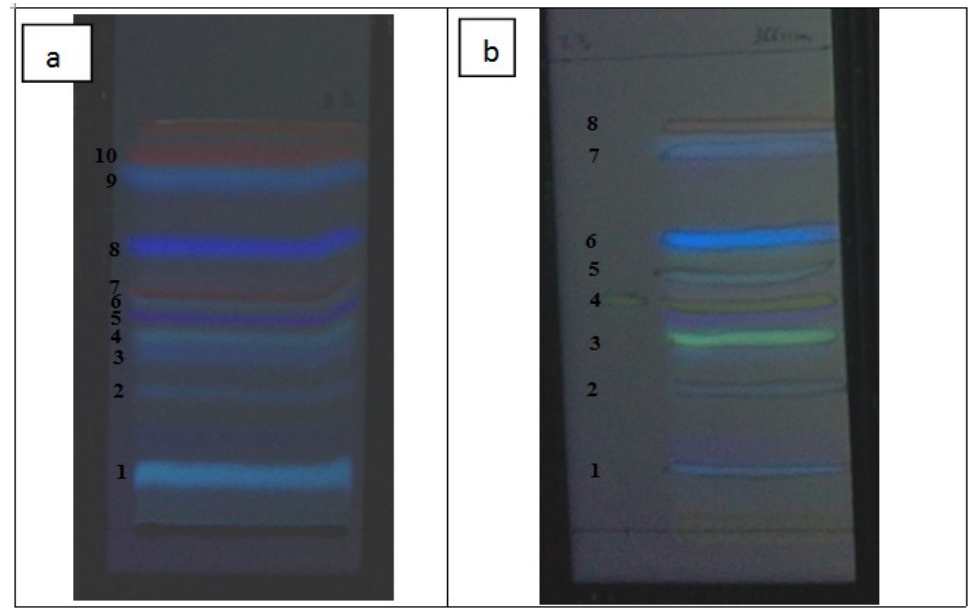

Figure 7. TLC of ficus leaf extracts (third band in $a$ is rutin; fourth band in $b$ is quercetin) after acid hydrolysis, under UV light $(366 \mathrm{~nm})$. Chromatography conditions:Run on glass-backed silica gel TLC GF254 pre-coated plate. Mobile phase:(toluene/ethyl acetate/formic acid) (9/8/0.2 v/v/v) for 30 minutes.

Identification of rutin, quercetin and qualitatively by MS and PDA spectrum. MS isoquercitrin in ficus leaf extracts by product ion spectra for $(\mathrm{M}-\mathrm{H})^{-}$ions of isolated HPLC- MS rutin, quercetin and isoquercitrin in ficus leaf The detection of isoquercitrin was done extracts are presented in Figure 8.

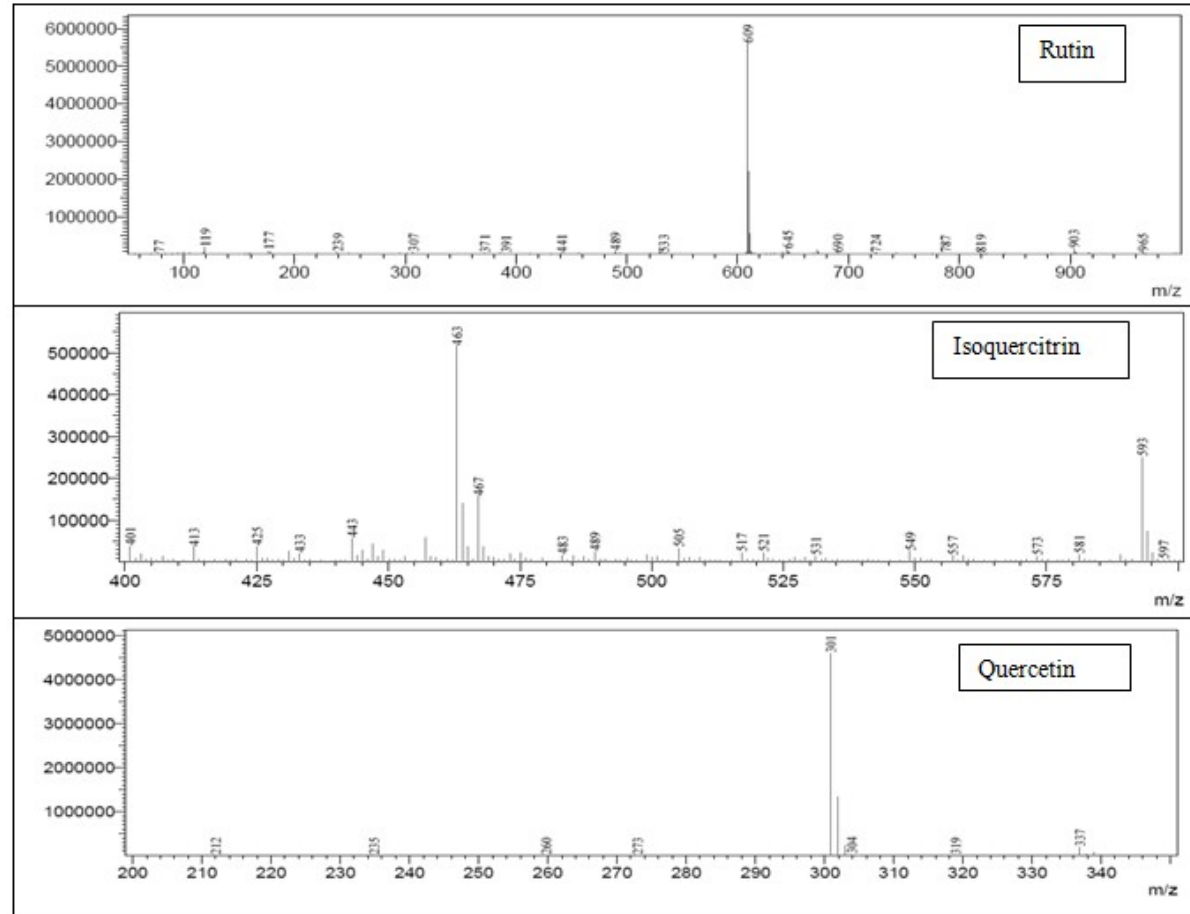

Figure 8. ESI-MS spectra of ficus leaf extracts' compounds in negative mode, interface temperature $350{ }^{\circ} \mathrm{C}$; dry gas (nitrogen) and nebulizing gas flow was $1.5 \mathrm{~L} / \mathrm{min}$. Detector and interface voltages were $0.5 \mathrm{KV}$ and $4.5 \mathrm{KV}$, respectively.

Identification of rutin, isoquercitrin and quercetin in extracts by HPLC-MS is presented in Table 3. 
Table 3. Retention time and $(\mathrm{M}-\mathrm{H})^{-}$ions of separated compounds from ficus leaf extracts by

\begin{tabular}{ccc} 
& HPLC-MS & \\
\hline Compound & R.t $(\min )$ & {$[\mathrm{M}-\mathrm{H}]^{-}(m / z)$} \\
\hline Rutin & 6.93 & 609 \\
Isoquercitrin & 7.41 & 463 \\
Quercetin & 11.39 & 301 \\
\hline
\end{tabular}

Isolation of rutin and quercetin from ficus extracts

The total ion chromatogram (TIC) of isolated rutin and quercetin in ficus leaf extracts by TLC, with those of standards are presented in Figure
9. It shows the perfect and successful isolation of these compounds. The relative peak areas for rutin and quercetin are 99.80 and $96.46 \%$, respectively.

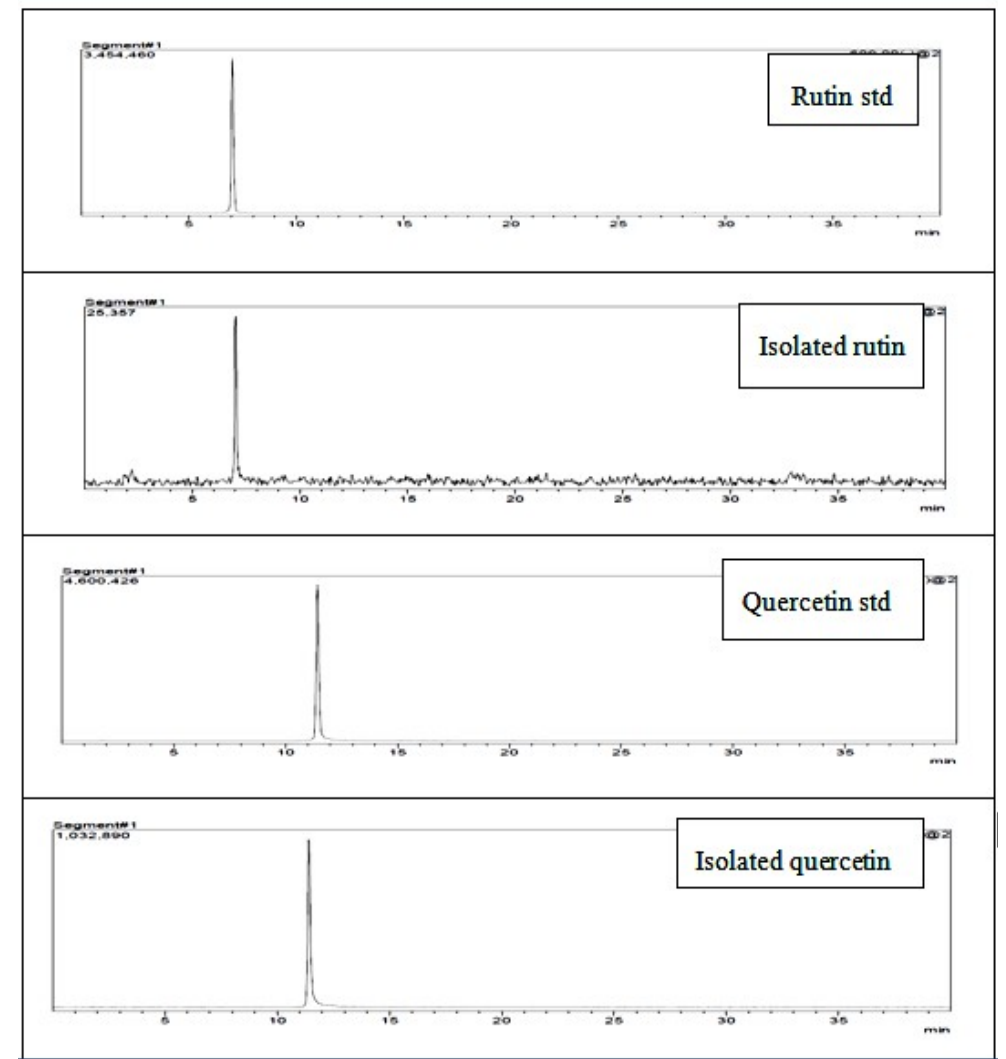

Figure 9. TIC of standards and isolated compounds from the ficus leaf extracts.

\section{CONCLUSION}

In this presented study, the compound plant (rutin) was extracted from Syrian ficus leaves by ultrasonic extraction procedure, then successfully converted into quercetin, which is the most powerful antioxidant compound. It was found that the solvent plays main role in the extraction of plant constituents. Ethanol $(70 \%)$ is less polar than water which means it is a better solvent for organic compounds. Therefore it extracted higher amount of flavonoids when compared to aqueous solvent. Best hydrolyzing time was chosen as 5 minutes, in order to preserve isoquercitrin in the extracts. Rutin and quercetin were identified by comparison with standards using chromatography. Both rutin and quercetin were successfully isolated from Syrian ficus leaf which is a cheap, available source, and identified by TLC, and HPLC-MS techniques.

\section{ACKNOWLEDGMENT}

The authors thank Mrs ALyamama Alaskar from the central laboratory in the faculty of scienceDamascus University for her help in MS data analysis. 


\section{REFERENCES}

1. Trifunschi S I, Munteanu M F F, Ardelean D G, Orodan $M$, Osser $G$ M, Gligor R I. Flavonoids and polyphenols content and antioxidant activity of Ficus carica L. extracts from Romania. Zbornik Matice srpske za prirodne nauke.2015; 128: 57-65.

2. Anonymous. The Agricultural Statistics Annual Group,2008. Directorate of Planning and Statistics, Statistics Division,Ministry of Agriculture and Agrarian Reform, Damascus,Syria. 2009.

3. Sirisha N, Sreenivasulu M, Sangeeta K, Chetty C M. Antioxidant Properties of Ficus Spesies - A Review, Int. J. Pharm. Tech. Res. 2010; 2: 2174 - 2182.

4. Solomon A, Golubowicz S, Yablowicz Z, Grossman S, Bergman M, Gottlieb H, et al. Antioxidant Activities and Anthocyanin Content of Fresh Fruits of Common Fig (Ficus carica L.). J. Agric. Food Chem. 2006; 54: 7717 - 7723.

5. Chawla A, Kaur R, Sharma A K. Ficus carica Linn.: A Review on its Pharmacognostic, Phytochemical and Pharmacological Aspects. Int. J. Pharm. Sci Res. 2012; 1: 215 - 232.

6. Rubnov $S$, Kashman $Y$, Rabinowitz R, Schlesinger M, Meehoulam R. Suppessors of Cancer Cell Proliferation from Fig (Ficus carica Linn.) Resin: Isolation and Structure Elucidation, J. Natu. Pro. 2001; 64: 993-996.

7. Kruzlicova D, Danihelova $M$, Veverka $M$. Quantitative structure-antioxidant activity relationship of quercetin and its new synthetised derivatives. Nova Biotechnologica et Chimica. 2012; 11: 37-44.

8. Yashin Ya I, Ryzhnev V Yu, Yashin A Ya, Chernousova $\mathrm{N}$ I. Prirodnye antioksidanty. Soderzhanie $v$ pishchevykh produktakh i ikh vliyanie na zdorov'ei starenie cheloveka. 2009.

9. Mauludin $\mathrm{R}$, Müller $\mathrm{R} H$, Keck $\mathrm{C} M$. Development of an oral rutin nanocrystal formulation. Int. J. Pharm Sci Res. 2009; 370: 202-209.

10. Chen H, Zuo Y, Deng Y. Separation and determination of flavonoids and other phenolic compounds in cranberry juice by highperformance liquid chromatography. J. Chrom A. 2001 ; 913: 387- 395.

11. Wang J, Zhao L L, Sun G X, Liang $Y$, Wu $F$ A, Chen Z I, et al . A comparison of acidic and enzymatic hydrolysis of rutin. African J. Biotech. 2011; 10: 1460-1466.

12. Seyoum A, Asres K, El-Fiky F K. Structureradical scavenging activity relationships of flavonoids. Phytochem. 2006; 67: 2058-2070.

13. Vaya J, Mahmood S. Flavonoid content in leaf extracts of the fig (Ficus carica L.), carob (Ceratonia siliqua L.) and pistachio (Pistacia lentiscus L.). Biofactors. 2006;28: 169-175.

14. Takahama U, Tanaka M, Hirota, S, Yamauchi $\mathrm{R}$. Formation of an oxathiolone compound from rutin in acidic mixture of saliva and buckwheat dough: Possibility of its occurrence in the stomach. Food Chem. 2009; 116: 214-219.

15. Kamalakkannan N, Stanely Mainzen P P. Antihyperglycaemic and antioxidant effect of rutin, a polyphenolic flavonoid, in streptozoticininduced diabetic wistar rats. Basic \& Clinical Pharm \& Toxi. 2006; 98: 97-103.

16. Je H D, Shin C Y, Park S Y, Yim SH, Kum C, Huh $\mathrm{I} \mathrm{H}$, et al. Combination of vitamin $\mathrm{C}$ and rutin on neuropathy and lung damage of diabetes mellitus rats. Archives. Pharm. Res. 2002; 25: 184-190.

17. Srinivasan K, Kaul C L, Ramarao P. Partial protective effect of rutin on multiple low dose streptozotocininduced diabetes in mice. Ind. J. Pharm. 2005; 37: 327- 328.

18. Li X, Park N I, Xu H, Woo SH, Park, CH, Park SU. Differential expression of flavonoid biosynthesis genes and accumulation of phenolic compounds in common buckwheat (Fagopyrum esculentum). J. Agri. Food Chem. 2010; 58: 12176- 12181.

19. Scherer RI, Godoy HT. Effects of extraction methods of phenolic compounds from Xanthium strumarium L. and their antioxidant activity. Revista Brasileira de Plantas Medicinais. 2014; 16: 41-46.

20. Zhang $Y$, Wang D, Yang L, Zhou D, Zhang J. Purification and characterization of flavonoids from the leaves of Zanthoxylum bungeanum and correlation between their structure and antioxidant activity. PLoS One. 2014; 9: e105725.

21. Makino $T$, Shimizu $R$, Kanemaru $M$, Suzuki $Y$, Moriwaki M, Mizukami $H$. Enzymatically modified isoquercitrin, a-oligoglucosyl quercetin 3-O-glucoside, is absorbed more easily than other quercetin glycosides or aglycone after 
oral administration in rats. Bio. Pharm Bull. 2009; 32: 2034-2040.

22. Erlund I. Review of the flavonoids quercetin, hesperetin, and naringenin. Dietary sources, bioactivities, bioavailability and epidemiology. Nut Res. 2004; 24: 851- 874.

23. Valentova $K$, Vrba J, Banciřova $M$, Ulrichova J, Křen $V$. Isoquercitrin: pharmacology, toxicology, and metabolism. Food. Chem. Toxi. 2014; 68: 267- 282.

24. Yi J, Wu J G, Wu Y B, Peng W. Antioxidant and anti-proliferative activities of flavonoids from Bidens pilosa $L$ var radiate Sch Bip. Tro. J. Pharm. Res.2016; 15: 341-348.

25. Achat S, Tomao V, Madani K, Chibane $M$, Elmaataoui $M$, Dangles $O$, et al. Direct enrichment of olive oil in oleuropein by ultrasound-assisted maceration at laboratory and pilot plant scale. Ultr. Sonochem. 2012; 19: 777-786.

26. Chen C, Zhou J, Ji C. Quercetin: A potential drug to reverse multidrug resistance. Life Sci. 2010; 87: 333-338.

27. Cimpoiu C. Analysis of some natural antioxidants by thin-layer chromatography and high performance thin-layer chromatography, J. Liquid Chrom Rel. Tech. 2006; 29: 1125-1142.

28. Şahin S, Şamlı R. Optimization of olive leaf extract obtained by ultrasound-assisted extraction with response surface methodology. Ultr. Sonochem. 2013; 20: 595-602. 